\title{
Infraspecific Variation of Huperzine A and B in Icelandic Huperzia selago Complex
}

\begin{abstract}
Authors
Maonian Xu ${ }^{1}$, Starri Heidmarsson ${ }^{2}$, Margret Thorsteinsdottir ${ }^{1}$, Pawel Wasowicz $^{2}$, Hang Sun ${ }^{3}$, Tao Deng ${ }^{3}$, Sesselja Omarsdottir ${ }^{1}$, Elin Soffia Olafsdottir ${ }^{1}$

Affiliations

1 Faculty of Pharmaceutical Sciences, University of Iceland, Reykjavik, Iceland

2 Akureyri Division, Icelandic Institute of Natural History, Akureyri, Iceland

3 Key Laboratory for Plant Biodiversity and Biogeography of East Asia, Kunming Institute of Botany, Chinese Academy of Sciences, Kunming, China

Key words Lycopodiaceae, Huperzia, huperzine A, huperzine B, phylogeny

received February 15, 2018

revised July 24,2018

accepted September 24, 2018

Bibliography

DOI https://doi.org/10.1055/a-0752-0295

Published online October 5, 2018 | Planta Med 2019; 85:

160-168 @ Georg Thieme Verlag KG Stuttgart · New York I

ISSN 0032-0943

Correspondence

Elin Soffia Olafsdottir, Ph.D., Professor

Faculty of Pharmaceutical Sciences, University of Iceland

Hagi, Hofsvallagata 53, 107 Reykjavik, Iceland

Phone: + 3545255804 , Fax: + 3545254071

elinsol@hi.is

Supporting information available online at

$\Theta$ http://www.thieme-connect.de/products

\section{ABSTRACT}

The alkaloids huperzine $A$ and huperzine $B$ were originally isolated from the Chinese club moss Huperzia serrata. They are known inhibitors of acetylcholinesterase, and especially huperzine A shows pharmaceutical potential for the treatment of Alzheimer's disease. Its supply heavily relies on natural plant sources belonging to the genus Huperzia, which shows considerable interspecific huperzine A variations. Furthermore, taxonomic controversy remains in this genus, particularly in the Huperzia selago group. With focus on Icelandic $H$. selago taxa, we aimed to explore the relatedness of Huperzia species using multi-locus phylogenetic analysis, and to investigate correlations between huperzine $A$ contents, morphotypes, and genotypes. Phylogenetic analysis was performed with five chloroplastic loci (the intergenic spacer between the photosystem II protein D1 gene and the tRNA-His gene, maturase $\mathrm{K}$, ribulose-1,5-bisphosphate carboxylase/ oxygenase large subunit, tRNA-Leu, and the intergenic spacer region between tRNA-Leu and tRNA-Phe). Huperzine A and huperzine B contents were determined using an HPLC-UV method. The phylogenetic analysis suggests that previously proposed Huperzia appressa and Huperzia arctica should not be considered species, but rather subspecies of $H$. selago. Three genotypes of Icelandic $H$. selago were identified and presented in a haplotype networking diagram. A significantly $(p<0.05)$ higher amount of huperzine $A$ was found in $\mathrm{H}$. selago genotype $3(264-679 \mu \mathrm{g} / \mathrm{g})$ than genotype $1(20-180 \mu \mathrm{g} /$ $\mathrm{g})$, where the former shows a typical green and reflexed "selago" morphotype. The huperzine A content in genotype 3 is comparable to Chinese $H$. serrata and a good alternative huperzine A source. Genotype 2 contains multiple morphotypes with a broad huperzine A content $(113-599 \mu \mathrm{g} / \mathrm{g})$. The content of huperzine B in Icelandic taxa $(6-13 \mu \mathrm{g} / \mathrm{g})$ is much lower than that in Chinese $H$. serrata $(79-207 \mu \mathrm{g} / \mathrm{g})$.
\end{abstract}

\section{Introduction}

Lycopodium alkaloids represent a diverse array of alkaloids specific to the club moss family Lycopodiaceae [1]. The club moss Huperzia serrata is used as a medicinal herb in China to treat several ailments, e.g., contusions and dementia [2]. The lycopodium alkaloids hupA and hupB shown in • Fig. 1 were first isolated from
H. serrata in 1980s [2]. They are potent AChE inhibitors, with hupA being considered a potential drug lead for the treatment of Alzheimer's disease [1-4]. Howerver, further pharmaceutical development is hampered by the lack of a sustainable resupply of the compound [3]. Although a series of techniques have been proposed, such as in vitro cultivation of Huperzia shoots [5], total synthesis [6], and fermentation of hupA-producing microbes [7], the 


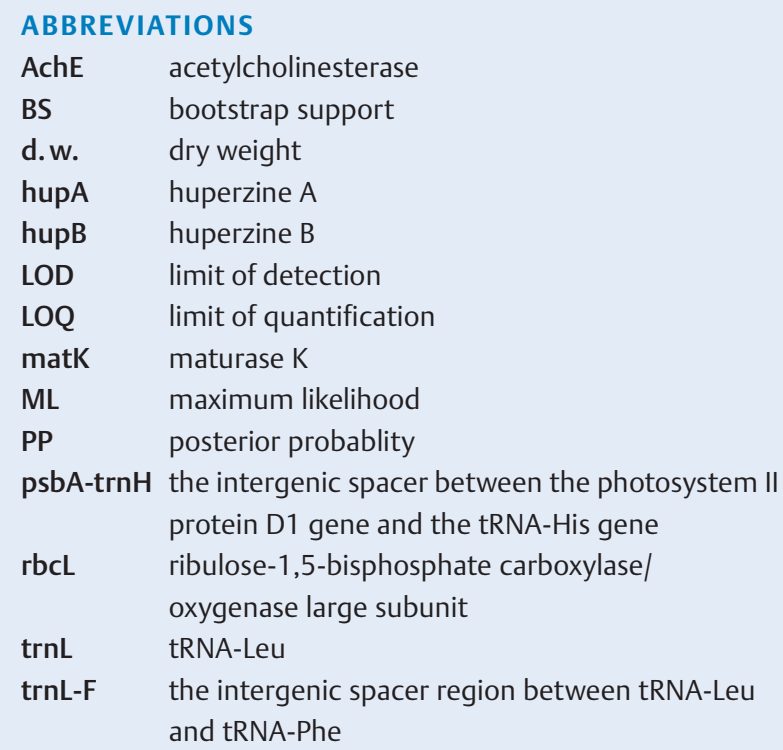

major source of hupA still heavily relies on herbal materials, which could lead to overharvesting $[4,8]$.

Since considerable variation of hupA content has been found in Huperzia species, it is important to identify the high hupA producers. In total, four club moss species grow in Iceland and one of them, Huperzia selago (L.) Bernh. Ex Schrank \& Mart., produces hupA [9]. The others are Diphasiastrum alpinum (L.) Holub, Spinulum annotinum (L.) A. Haines (Basionym: Lycopodium annotinum) [10], and Lycopodium clavatum (L.) [11]. The lycopodium alkaloids isolated and their in vitro inhibitory activity against AChE have been studied in Icelandic D. alpinum [12], S. annotinum [13], and H. selago [9]. HupA is by far the most potent AChE inhibitor of all tested lycopodium alkaloids with an $\mathrm{IC}_{50}$ value of $72.4 \mathrm{nM}$, while hupB has an $\mathrm{IC}_{50}$ value of $19.3 \mu \mathrm{M}[14]$.

The taxonomy of $H$. selago is still controversial, and phylogenetic analysis can be expected to resolve some of the issues. The genus Huperzia in the northern areas (boreal and arctic regions) is very polymorphic, and numerous taxonomical treatments have been published so far [15-18]. Some fairly recent European taxonomical treatments of Huperzia based on a hypothesis of gradual divergence of races within the genus $[15-17,19]$ have accepted one species of $H$. selago that includes two or three races, i.e., the temperate to boreal morphotype "selago" (spreading or patent, dentate, green to dark green leaves, and few, if any, bulbils), the more northerly distributed (northern alpine-boreal to southern arctic) morphotype "appressa" (appressed or subappressed, usually dentate leaves), and the most northerly distributed (arctic) morphotype "arctica" (brown leaves that were pressed outwards and bulbils present). Some European authors do not accept the morphotype "appressa" $[16,17]$ as a subspecies and include it in the subsp. arctica. These treatments include almost all taxonomically possible options ranging from recognition of one species (undifferentiated $H$. selago) and one species with local races (treated as subspecies) to the recognition of several independent species. Morphological differences between $H$. selago-related taxa
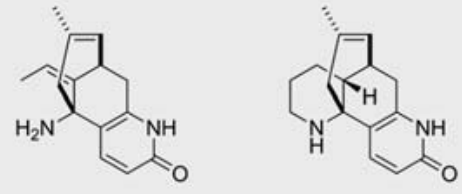

- Fig. 1 Chemical structure of huperzine A (left) and B (right).

might be trivial, with intermediate morphology being common, and thus they have been called the " $H$. selago group" [20]. This indicates that significant morphological and genetic variations are present within the genus, and that current taxonomical subdivisions of Huperzia are more or less provisional. Recent phylogenetic analyses of club mosses used chloroplastic DNA markers and revealed a phylogenetic relationship between genera and even species [20-23]. Species delimitation in those studies mainly focused on the sister genus Phlegmarirus [21,23], while the species level identification in the genus Huperzia was largely neglected.

In Iceland, "arctica" and "selago" morphotypes are regarded as $H$. selago subspecies [8], but the intermediate morphotype resembling the "appressa" morphotype can also be found. Subspecies arctica is commonly found in open areas with a yellow to yellowish-green color and outward pressed leaves, and subspecies selago usually grows in relatively humid and shady habitats with green to dark green shoots and reflexed leaves. Their taxonomic ranks comply with descriptions in the monograph Flora Nordica [17]. The subspecies selago is commonly found in western Iceland, while the subspecies arctica has a wider distribution [17]. It is timely to apply genetic tools to clarify this taxonomic uncertainty regarding the " $\mathrm{H}$. selago group", and to investigate the correlations between alkaloid contents, morphology, and genotypes.

Phytochemical studies of club mosses as well as other plants used for medical purposes should always be preceded by accurate identification of the plant material. It is also important to identify the plant species, cultivars, or even populations or genotypes correctly as they might vary considerably in alkaloid content. This study aimed to (1) explore species relatedness in the genus Huperzia using multi-locus phylogenetic analysis with a focus on the Icelandic $H$. selago complex, and determine whether this complex group should be recognized as one or more species or subspecies, (2) determine the contents of hupA and hupB in Icelandic Huperzia taxa, and explore correlations between hupA contents, morphotypes, genotypes, and phylogeny, and (3) compare the hupA and hupB contents between Icelandic Huperzia taxa and the widely consumed Chinese $\mathrm{H}$. serrata.

\section{Results}

Overall, 203 new sequences of five loci (i.e., psbA-trnH, rbcL, matK, trnL, and trnL-F) were generated in this study. With the newly designed primers, matK regions (ca. 800 bp) of sampled taxa were successfully amplified. The concatenated sequence matrix contained 3385 nucleotide characters with 595 variable sites. Our phylogenetic analysis recovered the genus Huperzia as 


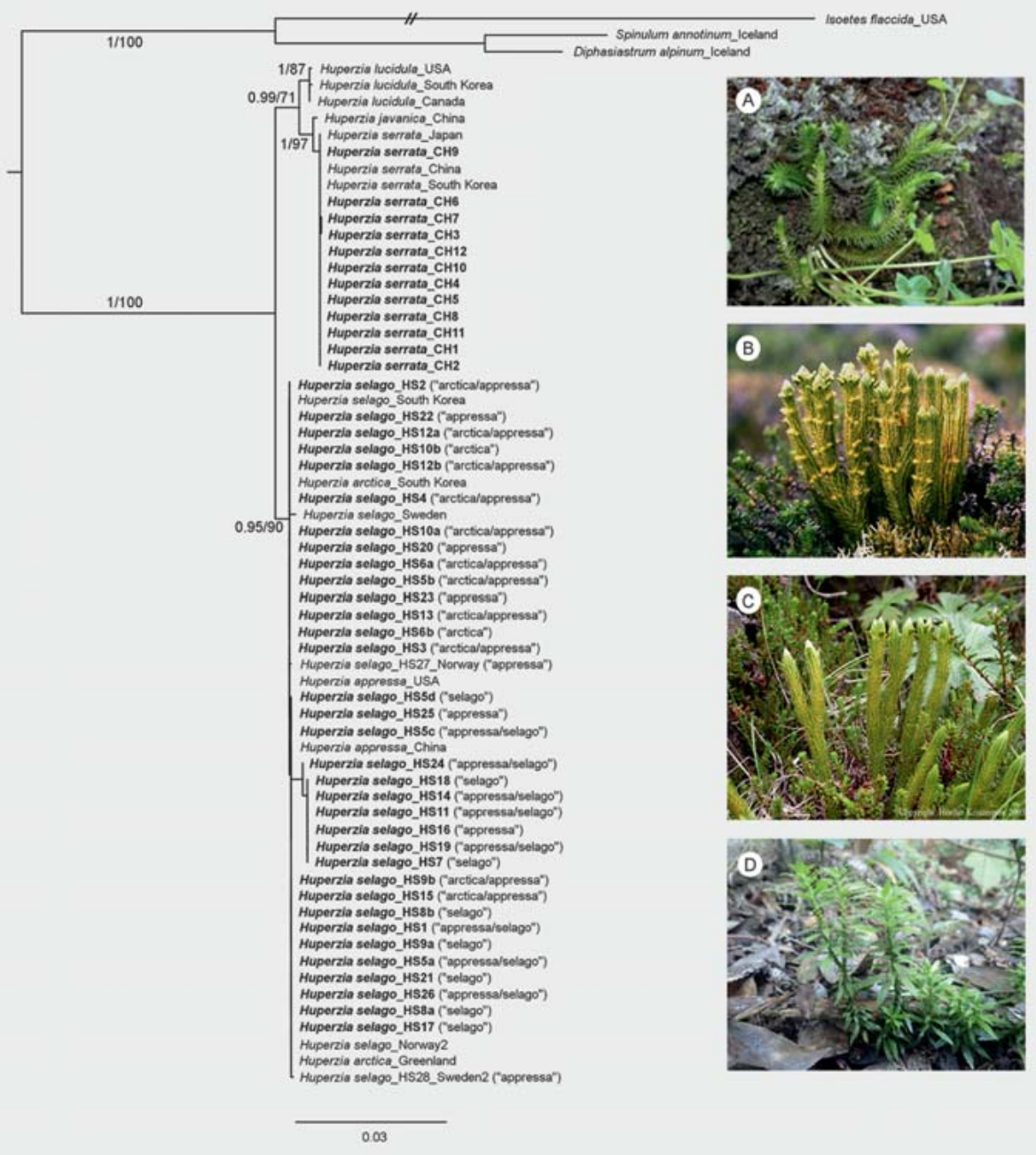

- Fig. 2 Maximum likelihood tree made from concatenated sequence matrix containing rbcL, matK, psbA-trnH, trnL, and trnL-F. Sampled Icelandic (HS1-26) and Chinese ( $\mathrm{CH} 1-12)$ club moss specimens are in boldface. $\mathrm{H}$. selago morphotypes are indicated in parentheses. Posterior probabilities (PP) over 0.95 and bootstrap (BS) values over $70 \%$ are labelled near branches as PP/BS. Representative photographs of sampled taxa including (A) H. selago ssp. selago (i.e., "selago" morphotype), (B) H. selago ssp. arctica (i.e., "arctica" morphotype), (C) H. selago ssp. appressa (i.e., "appressa" morphotype), and (D) H. serrata. Photos were taken by Natalia Kowal (A), Hördur Kristinsson (B, C) and Cheng Zhang (D).

a monophyletic clade with a BS value of $100 \%$ and a PP of 1 ( $\bullet$ Fig. 2). A deeper subgeneric relationship of Huperzia species was uncovered showing that the temperate taxa $\mathrm{H}$. serrata, Huperzia javanica, and Huperzia lucidula are more closely related to each other and form a sister clade (BS: 71; PP: 0.99) to the circumpolar species $H$. selago. Previously proposed morphological species Huperzia arctica and Huperzia appressa are not distinct and form a monophyletic clade (BS: 90; PP: 0.95) with $H$. selago.

The alkaloids hupA and hupB ( $\bullet$ Fig. 1 ) were identified by comparing their retention times $\left(t_{R}=9.0 \mathrm{~min}\right.$ and $4.5 \mathrm{~min}$, respectively) ( Fig. 3A) with those of commercial standards. The HPLC method showed good performance in separating hupA and hupB $\left(\triangleright\right.$ Fig. 3A). Good linearity was obtained $\left(R^{2}=0.9918-0.9986\right)$ in the working linear range of $0.2-25 \mu \mathrm{g} / \mathrm{mL}$ for both compounds. LOD and LOQ were determined at 0.04 and $0.1 \mu \mathrm{g} / \mathrm{mL}$ for hupB, and 0.06 and $0.15 \mu \mathrm{g} / \mathrm{mL}$ for hupA, respectively. Intraday and in- ter-day variations (measured as relative standard deviation) were $0.5-3.8 \%$ and $2.1-6.4 \%$, respectively. A good recovery of $92-$ $105 \%$ was obtained for both compounds.

The contents of hupA in the sampled Huperzia specimens showed a considerable variation ranging from 20.63-679.82 $\mu \mathrm{g} /$ g d.w. ( Table 1). Low hupA contents (ca. $20-110 \mu \mathrm{g} / \mathrm{g}$ d.w.) are mostly associated with the "arctica" morphotype, while high hupA contents (ca. 260-680 $\mu \mathrm{g} / \mathrm{g}$ ) are associated with the "selago" morphotype. The correlation between genotypes and hupA contents in Icelandic specimens was studied and compared using a haplotype network diagram ( $\bullet$ Fig. 4 ). It was found that genotype $3(264.39-679.82 \mu \mathrm{g} / \mathrm{g}$ d.w.) contained a significantly $(p<0.05)$ higher amount of hupA than genotype 1 (20.63$193.84 \mu \mathrm{g} / \mathrm{g}$ d.w.). Genotype 3 is a "selago" morphotype with one exception of an "appressa" morphotype, while genotype 1 is uniformly an "arctica" morphotype. The intermediate genotype 2 

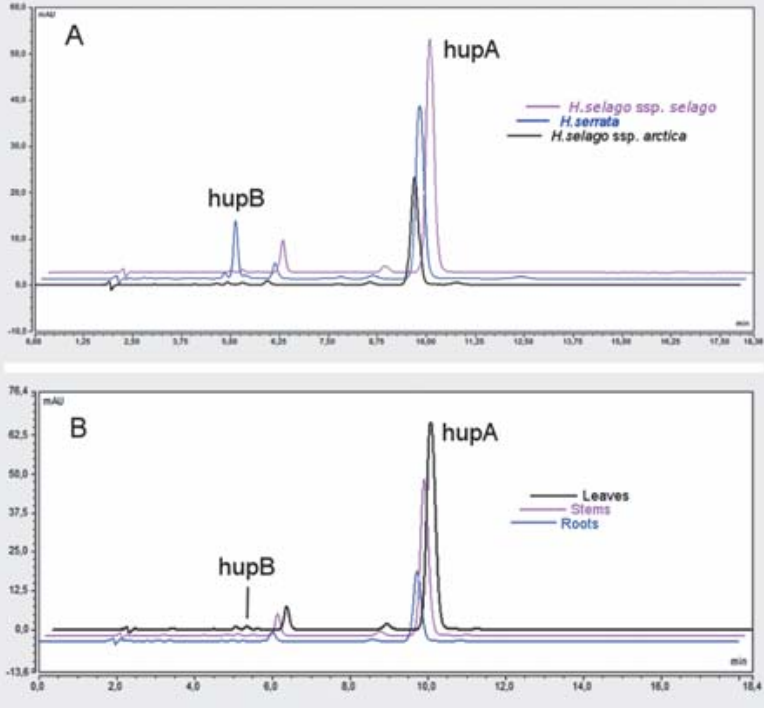

- Fig. 3 HPLC-UV chromatograms showing (A) hupA and hupB variations between two $H$. selago subspecies and $H$. serrata, and (B) tissue-dependent hupA contents in H. selago ssp. selago.
Although the morphological distinction of some $\mathrm{H}$. selago specimens into one of the three morphotypes can be challenging, as reflected in Table S1, Supporting Information, and $>$ Table 1, it seems that the "arctica" and "selago" morphotypes tend to have their own genetic identity as do genotypes 1 and 3 in the haplotype network diagram. This also correlates with hupA contents: low in the former and high in the latter. The presence of intermediate genotype 2 with mixed and intermediate morphotypes may indicate hybridization, which has been shown to be common among Huperzia species [28].

Variation of hupA contents in Icelandic $H$. selago (20.63$679.82 \mu \mathrm{g} / \mathrm{g} \mathrm{d}$. w.) is within the range of reported amounts in the literature, such as hupA in Australian Huperzia species (0$1.03 \mathrm{mg} / \mathrm{g} \mathrm{d.w.)}$ [5] and Chinese taxa (46.85-254.58 $\mu \mathrm{g} / \mathrm{g})$ [29]. The highest concentration of hupA reported in wild Huperzia species is $1.27 \mathrm{mg} / \mathrm{g} \mathrm{d}$. w. in a Polish $H$. selago specimen [5]. Our results of hupA contents in sampled Chinese $H$. serrata (318.71$593.50 \mu \mathrm{g} / \mathrm{g} \mathrm{d}$.w.) are, however, much higher than the reported range $(80.16-182.55 \mu \mathrm{g} / \mathrm{g})$ [29]. Such variation might be due to the insufficient drying and grinding of plant materials in the reference study, where plant materials are only air-dried and ground without the assistance of liquid nitrogen, which altogether leads to a lower concentration of hupA. Furthermore, different sample preprocessing methods (e.g., storage and grinding, etc.), solvents, and extraction time might contribute to such variations. Another reason might be the inaccurate identification of plant materials in the reference study, where no morphological or genetic data were shown.

A study on Chinese Huperzia species and related taxa suggests that the genus Phlegmariurus $(241.84-560.46 \mu \mathrm{g} / \mathrm{g})$ should be a better source of hupA than its sister genus Huperzia (46.85$254.58 \mu \mathrm{g} / \mathrm{g}$ ) [29]. Other studies have shown the contrary, i.e., no detectable amount of hupA were found in Australian Phlegmariurus phlegmaria and Phlegmariurus tetrastrichus [5]. Phlegmariurus species in the latter study are from Nursery stock, while the taxa in the former study are wild. Future studies should investigate the possible influence of environmental conditions and seasonal fluctuation on the production of hupA. In addition, the current study also supported the tissue-dependent distribution of hupA, which is concentrated in the aerial part. A high content of hupA $(415 \mu \mathrm{g} / \mathrm{g})$ in spore-bearing leaves (i.e., sporophyte) has been reported [30]. Samples in the current study were mostly collected in late summer and early September when spores have been released, so an early sampling strategy in spring may be considered to compare seasonal variation with and without spores.

Considerable hupB variation has been reported in Huperzia and Plagmarius species ranging from 0 to $302 \mu \mathrm{g} / \mathrm{g}$ [31,32], and our results of $5.97-12.92 \mu \mathrm{g} / \mathrm{g}$ for $H$. selago and $78.74-206.67 \mu \mathrm{g} / \mathrm{g}$ for $H$. serrata fall within this range. Although hupB is a relatively strong $A C h E$ inhibitor $\left(I_{50}: 19.3 \mu \mathrm{M}\right)$, its content in the plants is usually much lower than the more potent hupA ( $\left.\mathrm{IC}_{50}: 72.4 \mathrm{nM}\right)$ $[14,29]$, and therefore hupB has gained much less attention. The large hupB differences between Icelandic $H$. selago and Chinese $H$. serrata can result from both environmental and genetic factors.

To conclude, our phylogenetic analysis suggests that previously proposed $H$. appressa (i.e., "appressa" morphotype) and H. arctica (i.e., "arctica” morphotype) should be regarded as sub- 
- Table 1 HupA and hupB contents in sampled Huperzia species ${ }^{\mathrm{a}}$.

\begin{tabular}{|c|c|c|c|c|}
\hline SampleID ${ }^{b}$ & Herbarium No. & Morphotypesc & HupA $(\mu g / g)^{d}$ & HupB $(\mu g / g)^{e}$ \\
\hline HS1_G2 & VA21570 & appressa/selago & $179.41 \pm 1.71$ & n.d. \\
\hline HS2_G1 & VA21571 & arctica/appressa & - & - \\
\hline HS3_G1 & VA21572 & arctica/appressa & $180.37 \pm 16.42$ & n.d. \\
\hline HS4_G1 & VA21573 & arctica/appressa & $83.33 \pm 10.56$ & n.d. \\
\hline HS5a_G2 & VA21574 & appressa/selago & $214.82 \pm 23.35$ & n.d. \\
\hline HS5b_G1 & VA21575 & arctica/appressa & $150.76 \pm 12.37$ & n.d. \\
\hline HS5c_G2 & VA21576 & appressa/selago & $428.40 \pm 11.33$ & n.d. \\
\hline HS5d_G2 & VA21577 & selago & $277.11 \pm 16.23$ & n.d. \\
\hline HS6a_G1 & VA21578 & arctica/appressa & $58.36 \pm 6.80$ & n.d. \\
\hline HS6b_G1 & VA21579 & arctica & $31.98 \pm 1.85$ & n.d. \\
\hline HS7_G3 & VA21580 & selago & $306.22 \pm 21.85$ & n.d. \\
\hline HS8a_G2 & VA21581 & selago & $333.06 \pm 31.82$ & n.d. \\
\hline HS8b_G2 & VA21582 & selago & $271.41 \pm 4.00$ & $9.07 \pm 0.09$ \\
\hline HS9a_G2 & VA21583 & selago & $242.86 \pm 28.77$ & n.d. \\
\hline HS9b_G2 & VA21584 & arctica/appressa & $113.14 \pm 7.23$ & n.d. \\
\hline HS10a_G1 & VA21585 & arctica/appressa & $20.63 \pm 2.80$ & n.d. \\
\hline HS10b_G1 & VA21586 & arctica & $28.63 \pm 2.61$ & n.d. \\
\hline HS11_G3 & VA21587 & appressa/selago & $477.01 \pm 6.65$ & $6.72 \pm 0.44$ \\
\hline HS12a_G1 & VA21588 & arctica/appressa & $64.88 \pm 10.09$ & n.d. \\
\hline HS12b_G1 & VA21589 & arctica/appressa & - & - \\
\hline HS13_G1 & VA21590 & arctica/appressa & - & - \\
\hline HS14_G3 & VA21591 & appressa/selago & $264.39 \pm 18.86$ & n.d. \\
\hline HS15_G2 & VA21592 & arctica/appressa & $285.24 \pm 17.29$ & n.d. \\
\hline HS16_G3 & VA21593 & appressa & $413.02 \pm 41.66$ & n.d. \\
\hline HS17_G2 & VA21594 & selago & $517.77 \pm 33.65$ & $5.97 \pm 0.53$ \\
\hline HS18_G3 & VA21595 & selago & $679.82 \pm 16.25$ & $8.91 \pm 0.95$ \\
\hline HS19_G3 & VA21596 & appressa/selago & $336.27 \pm 34.06$ & n.d. \\
\hline HS20_G1 & VA21597 & appressa & - & - \\
\hline HS21_G2 & VA21598 & selago & $599.77 \pm 40.55$ & n.d. \\
\hline HS22_G1 & VA21599 & appressa & - & - \\
\hline HS23_G1 & VA21600 & appressa & $159.09 \pm 8.40$ & n.d. \\
\hline HS24_G3 & VA21601 & appressa/selago & $631.99 \pm 27.92$ & $12.92 \pm 1.77$ \\
\hline HS25_G2 & VA21602 & arctica/selago & - & - \\
\hline HS26_G2 & VA21603 & appressa/selago & $599.63 \pm 35.29$ & n.d. \\
\hline HS27_G1 & VA21604 & appressa & - & - \\
\hline HS28_G2 & VA21605 & arctica/appressa & - & - \\
\hline $\mathrm{CH} 2$ & VA21607 & - & $543.10 \pm 16.51$ & $195.14 \pm 17.71$ \\
\hline $\mathrm{CH} 3$ & VA21608 & - & $593.50 \pm 35.03$ & $143.94 \pm 8.87$ \\
\hline $\mathrm{CH} 5$ & VA21610 & - & $568.29 \pm 13.88$ & $206.67 \pm 5.00$ \\
\hline $\mathrm{CH} 9$ & VA21614 & - & $318.71 \pm 10.90$ & $78.74 \pm 9.47$ \\
\hline
\end{tabular}

a Specimens of small quantity (i.e., less than $0.3 \mathrm{~g}$ ) were only used for phylogenetic investigation but not hupA and hupB determination; ${ }^{\mathrm{b}} \mathrm{Genotypes} \mathrm{G} 1, \mathrm{G} 2$, and $\mathrm{G} 3$ refer to $\mathbf{F i g . ~ 4 ; ~ ' ~}$ Morphotype assignment refers to the morphological description in the "Introduction" section; ${ }^{\mathrm{d}, \mathrm{e}}$ HupA and hupB contents in specimens were shown as dry weight matters 


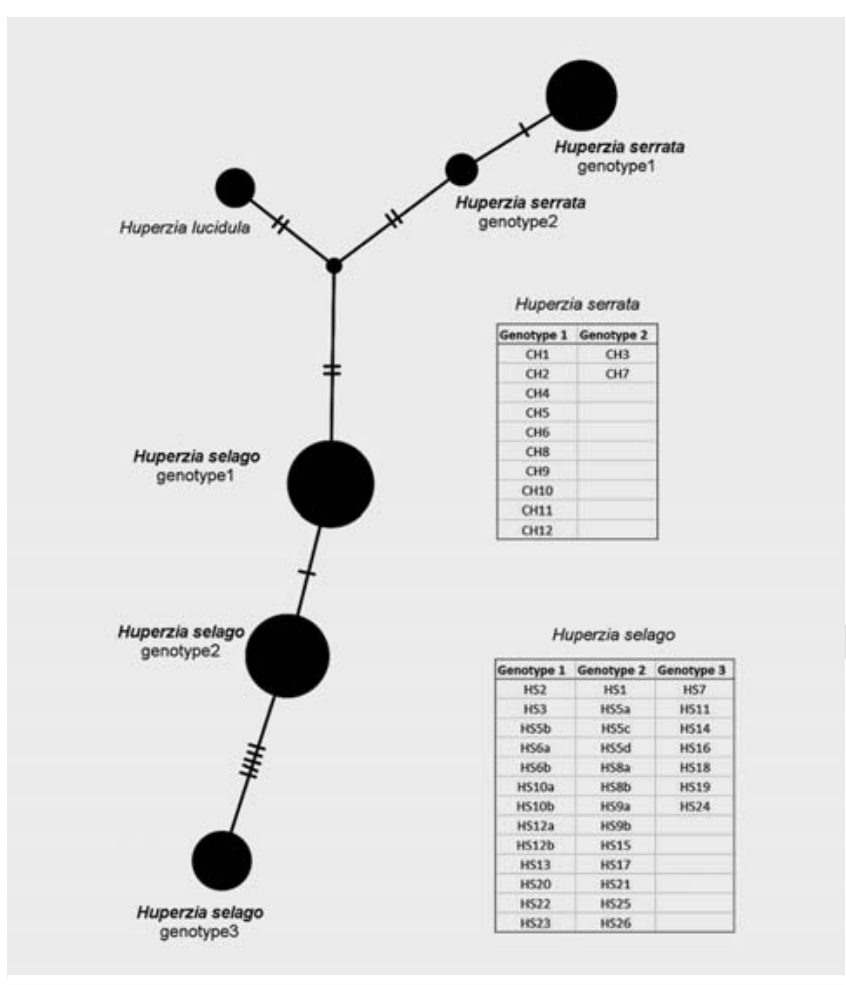

- Fig. 4 A haplotype network diagram displaying genotypes of Icelandic $\mathrm{H}$. selago taxa including three genotypes. Specimens (see - Table 1) under each genotype are indicated.

species of $H$. selago. HupA content differs substantially in the three genotypes found within the Icelandic $H$. selago complex. Genotype 3 corresponding to the "selago" morphotype consistently contains a high amount of hupA, and genotype 1 corresponding to the "arctica" morphotype contains a significantly $(p<0.05)$ lower amount of hupA. Genotype 3 of $\mathrm{H}$. selago can be considered a good alternative hupA source to the widely consumed Chinese $H$. serrata, but hupB content turned out to be much lower in the $H$. selago specimens than that in $H$. serrata. The results emphasize the importance of carefully identifying plant materials down to the subspecies and genotype level, especially for medicinal plants aimed for human consumption or extraction of valuable compounds such as hupA and hupB.

\section{Materials and Methods}

\section{Chemicals and biochemicals}

Acetic acid, ammonium acetate, dichloromethane, and methanol were purchased from Sigma-Aldrich. Organic solvents are of HPLC grade. Commercial standard compounds huperzine A and B (purity $>99 \%$ by HPLC) were from PhytoLab GmbH\&Co. KG. A Plant DNeasy Mini Kit was purchased from Qiagen. Taq DNA polymerase was from New England Biolabs. Gel stain SYBR safety was from Invitrogen. Exonuclease I (EXO) and Shrimp alkaline phosphatase (SAP) were from Fermentas.

\section{Plant materials and sampling}

In total, 58 specimens were collected for the current study. Among them, 34 specimens of Icelandic $H$. selago were collected around Iceland, including morphotypes "selago", "appressa”, and "arctica” (see below for description). Additional two Scandinavian H. selago specimens with an "appressa" morphotype were kindly provided by Dr. Hugo de Boer (Natural History Museum, University of Oslo). The species D. alpinum (four specimens) and S. annotinum (six specimens) were also collected, as they were used for phylogenetic analysis as an outgroup [22]. In addition, Chinese H. serrata (Thunb.) Trevis (12 specimens) was included in the current study in order to compare the hupA and hupB contents between the widely used $H$. serrata and Icelandic $H$. selago. Vouchers of all collected specimens are deposited in the Icelandic Institute of Natural History, Akureyri Division (AMNH) under the herbarium numbers VA20570-21629. H. selago specimens were distinguished to three morphotypes referring to their description in the "Introduction" section. Representative photos of the morphotypes are shown in $\mathbf{F i g}$. $\mathbf{2}$ A-C. Intermediate morphotypes were also commonly found, as reported by other taxonomists [17], and were assigned as "arctica/appressa" or "appressa/selago" (Table 1S, Supporting Information).

Assignment of morphotypes is shown in Table 1S, Supporting Information, and - Table 1, together with voucher information and GenBank accession numbers. Plant materials for downstream DNA extraction and chemical analysis were dried in silica gel and air-dried for 10 days, respectively. Dried plant materials were stored in darkness at room temperature. Specimens of small quantity (i.e., less than $0.2 \mathrm{~g}$ ) were only used for the phylogenetic investigation and deposited in herbarium.

\section{Sample preparation for alkaloid analysis}

Air-dried plant materials (ca. $0.3-0.5 \mathrm{~g}$ ) were ground in liquid nitrogen into fine powders. Then, pulverized materials were lyophilized overnight before alkaloid extraction. Lyopholized materials were accurately weighed $(40 \mathrm{mg})$ in glass tubes, and the alkaloids were extracted in a sonicator for 30 min with $0.9 \mathrm{~mL} 2 \%$ acetic acid in Milli-Q water. Organic solvents were not used due to the lower extraction efficiency of hupA [29]. Extraction was repeated twice and all extracts were combined and washed twice with dichloromethane. The supernatant was transferred to another glass tube, and $0.9 \mathrm{~mL}$ dichloromethane was added. The $\mathrm{pH}$ of the aqueous layer was adjusted to 9-10 with ammonium hydroxide. The organic layer was separated, and the aqueous layer was then extracted two times with dichloromethane. All three organic layers were combined and evaporated under reduced pressure. Dried residues were dissolved in methanol and filtered $(0.45 \mu \mathrm{m}$; Millipore) before the HPLC analysis. Alkaloid extraction of each specimen was carried out in triplicate.

\section{Quantitation of huperzine A and B}

An HPLC method was developed following a reported procedure [20] with minor modifications to determine hupA and hupB contents in club moss samples. Chromatographic analysis was carried out using the Dionex UltiMate 3.0 HPLC system, controlled by Dionex Chromeleon software v7.2. The HPLC system consisted of a column oven compartment, an autosampler with temperature 
- Table 2 Primers and their annealing temperatures.

\begin{tabular}{|l|l|l|l|}
\hline Primer & Sequence $\mathbf{( 5}^{\prime} \mathbf{- 3}^{\prime} \mathbf{)}$ & $\mathbf{T}_{\mathbf{a}}$ & Reference \\
\hline rbcL-1F & ATGTCACCACAAACGGA & 55 & {$[24]$} \\
\hline rbcL-1409R & TCAAATTCAAACTTGATTTCTTTCCA & {$[24]$} & {$[38]$} \\
\hline psbA-F & GTTATGCATGAACGTAATGCTC & 50 & {$[39]$} \\
\hline trnH-2R & CGCGCATGGTGGATTCACAATC & 51 & This study \\
\hline Hup-matK-F & TGGAGGACCATTTTTCACAT & & This study \\
\hline Hup-matK-R & TTAAATTGGTTAGGATGTCA & 51 & {$[40]$} \\
\hline B49317 & CGAAATCGGTAGACGCTACG & & {$[40]$} \\
\hline A50272 & ATTTGAACTGGTGACACGAG & & \\
\hline
\end{tabular}

control, an UltiMate 3000 pump, and an UltiMate 3000 photodiode array detector. Separation of alkaloids was performed on an Eclipse XDB-C18 column $(4.6 \times 150 \mathrm{~mm}, 5 \mu \mathrm{m}$; Agilent). The column oven was kept at $30^{\circ} \mathrm{C}$, and the autosampler at $10^{\circ} \mathrm{C}$. The mobile phase contained $\mathrm{MeOH}$ :ammonium acetate buffer (15 mM, pH 5.5) (25:75, v/v). Each sample of $20 \mu \mathrm{L}$ injection volume was run using isocratic elution for $18 \mathrm{~min}$. The flow rate was $0.8 \mathrm{~mL} / \mathrm{min}$. A standard mixture containing $50 \mu \mathrm{g} / \mathrm{mL}$ hupA and $50 \mu \mathrm{g} / \mathrm{mL}$ hupB in methanol was prepared, followed by the preparation of a series of standard dilutions $(0.5,1,2.5,5,10$, and $25 \mu \mathrm{g} / \mathrm{mL}$ ) of hupA.

Validation of the HPLC method included the LOD (signal-tonoise ratio $=3: 1$ ), LOQ (signal-to-noise ratio $=9: 1$ ), linearity of the calibration curve and linear range, and a precision and recovery test. Precision was evaluated as intraday and inter-day precision by analyzing the standard dilutions at concentrations from 1 to $50 \mu \mathrm{g} / \mathrm{mL}$ in five replicates. To measure the loss of hupA during sample preparation, a recovery test of hupA was performed. Lyophilized plant materials $(40 \mathrm{mg})$ were spiked with a known amount of hupA and hupB (10 $\mathrm{\mu g}$ for each) before extraction. The peak areas of spiked and unspiked samples were used to calculate the percentage recovery (R\%). Recovery tests were carried out in five replicates.

$\mathrm{R} \%=\frac{\text { Peak area (spiked before extraction) }- \text { peak area (unspiked) }}{\text { Peak area (spiked after extraction) }- \text { peak area (unspiked) }} \times 100 \%$

\section{DNA extraction, PCR, and sequencing}

Total genomic DNA was extracted from silica-dried plant materials (ca. 15-20 mg) using a Qiagen DNeasy Plant Mini Kit following the manufacturer's instructions. Three chloroplast loci were amplified using PCR, including psbA-trnH, rbcL, matK, trnL, and trnL-trnF. Primers of the loci psbA-trnH, rbcL, trnL, and trnL-F were chosen from published articles, while two new matK primers were designed (Oligo, v7; National Biosciences Inc.) to amplify the partial matK-encoding region. The design of the new matK primers refers to published whole chloroplast genomes of $H$. serrata (NC033874) and $H$. lucidula (NC006861) as well as complete or partial matK regions of other club moss species (DQ465956DQ465964, KT821301-KT821304, and EU749488-EU749492). Primer sequences and their annealing temperatures are listed in - Table 2.
- Table 3 Statistics of sequence alignment.

\begin{tabular}{|l|l|l|l|}
\hline Partitions & $\begin{array}{l}\text { Length } \\
\text { (base pair) }\end{array}$ & $\begin{array}{l}\text { Variable } \\
\text { characters }\end{array}$ & $\begin{array}{l}\text { Substitution } \\
\text { model }\end{array}$ \\
\hline rbcL & 1278 & 191 & TRN+C \\
\hline psbA-trnH & 317 & 51 & HKY+I \\
\hline matK & 777 & 279 & TVM+I \\
\hline trnL & 423 & 55 & K81UF \\
\hline trnL-F & 590 & 19 & HKY+I \\
\hline & & & \\
\hline & & & \\
\end{tabular}

The PCR master mix $(25 \mu \mathrm{L})$ contained $1 \times$ standard Taq DNA polymerase, $2.5 \mu \mathrm{L}$ standard PCR reaction buffer, 1-3 $\mu \mathrm{L}$ DNA template, $200 \mu \mathrm{M}$ dNTPs, $0.2 \mu \mathrm{M}$ forward/reverse primer, and PCR-grade water. PCR conditions for rbcL and psbA-trnH were as follows: an initial denaturation at $94^{\circ} \mathrm{C}$ for 3 min, then 32 cycles of $94^{\circ} \mathrm{C}$ for $50 \mathrm{~s}, 55^{\circ} \mathrm{C}$ (rbcL) or $53^{\circ} \mathrm{C}$ (psbA-trnH) for $50 \mathrm{~s}$, and $68^{\circ} \mathrm{C}$ for $1 \mathrm{~min}$, followed by a final extension of $5 \mathrm{~min}$. The amplification of matK and trnL \& trnL-F regions used a touchdown PCR program: $94^{\circ} \mathrm{C}$ for $3 \mathrm{~min}$, six cycles of $94^{\circ} \mathrm{C}$ for $50 \mathrm{~s}, 55-50{ }^{\circ} \mathrm{C}$ (decreasing $1^{\circ} \mathrm{C}$ per cycle) for $50 \mathrm{~s}$, and $68^{\circ} \mathrm{C}$ for $1 \mathrm{~min}$, then 30 cycles of $94^{\circ} \mathrm{C}$ for $50 \mathrm{~s}, 55-50^{\circ} \mathrm{C}$ (decreasing $1{ }^{\circ} \mathrm{C}$ per cycle) for $50 \mathrm{~s}$, and $68^{\circ} \mathrm{C}$ for $1 \mathrm{~min}$, followed by a final extension at $68^{\circ} \mathrm{C}$ for $7 \mathrm{~min}$. Gel electrophoresis of PCR products used $1.3 \%$ agrose stained by SYBR Safe DNA stain. Successfully amplified PCR products were subjected to EXO-SAP purification before Sanger sequencing by Macrogen Inc. The same sets of forward and reverse $\mathrm{PCR}$ primers were used for sequencing.

\section{Phylogenetic and haplotype network analysis}

Genetic sequences of 65 specimens were subjected to phylogenetic analysis, which included newly generated sequences from 50 collected Icelandic and Chinese specimens and reference sequences of 15 specimens from GenBank (Table S1, Supporting Information). Sequence assembly and primary sequence alignment were performed using PhyDe-Phylogenetic Data Editor version 0.9971. Multiple sequence alignments of three loci were then conducted using MAFFT v7 [33], followed by manual refinement. Alignment data are summarized in $>$ Table 3. 
A concatenated sequence matrix was used to infer the phylogeny of the club mosses. Before that, a gene tree of each locus was estimated using an ML method to see if there were incongruences of tree topology. No well-supported incongruences were observed, and the sequences of five loci were concatenated. ML analysis was performed using the software RaxML GUI v1.3 [34]. In total, 1000 bootstrap pseudoreplicates were used to estimate nodal support values, and the GTRGAMMA model was implemented. Two partition schemes were compared: (1) the whole psbA-trnH and the 1st, 2nd, and 3rd condon position of rbcL and matK, and (2) each locus as a single partition. Similar nodal support values were generated using both partition schemes, and the 2 nd partition scheme was used for downstream phylogenetic analysis. Nucleotide substitution models of each locus was estimated using jModeltest. Bayesian trees were constructed using the software MrBayes v3.2.6 [35], and the analysis was conducted for 10 million generations with the first $25 \%$ of the tree discarded. The software FigTree v1.4.2 was used for the visualization of the phylogenetic trees. Branches with BS values over $70 \%$ and PP values over $95 \%$ were considered well supported.

A TCS haplotype network diagram [36] was created using the software POPART v1.7 [37] to visualize the subspecies-level relationships of Icelandic $H$. selago taxa. Individual genotypes were identified and specimens under each genotype were also represented.

\section{Supporting information}

Voucher information and GenBank accession numbers of sequenced loci are provided as Supporting Information.

\section{Acknowledgements}

The People Programme (Marie Curie Actions) of the European Union's Seventh Framework Programme FP7/2007-2013 (grant number 606895) and the Icelandic Research Fund (grant number 152604051) are acknowledged for financial support. This study was also funded from the Bergthora and Thorsteinn Scheving Thorsteinsson Fund.

\section{Conflict of Interest}

The authors declare no conflict of interest.

\section{References}

[1] Ma X, Gang DR. The Lycopodium alkaloids. Nat Prod Rep 2004; 21: $752-$ 772

[2] Ma X, Tan C, Zhu D, Gang DR, Xiao P. Huperzine A from Huperzia speciesAn ethnopharmacolgical review. J Ethnopharmacol 2007; 113: 15-34

[3] Olafsdottir ES, Halldorsdottir ES, Pich N. Lycopodium Alkaloids: Pharmacology. In: Ramawat KG, Mérillon JM, eds. Natural Products. Berlin, Heidelberg: Springer; 2013: 343-358

[4] Ma X, Tan C, Zhu D, Gang DR. A survey of potential huperzine A natural resources in China: the Huperziaceae. J Ethnopharmacol 2006; 104: 5467

[5] Szypula W, Pietrosiuk A, Suchocki P, Olszowska O, Furmanowa M, Kazimierska O. Somatic embryogenesis and in vitro culture of Huperzia selago shoots as a potential source of huperzine A. Plant Sci 2005; 168: 1443-1452
[6] Siengalewicz P, Mulzer J, Rinner U. Lycopodium alkaloids - synthetic highlights and recent developments. Alkaloids Chem Biol 2013; 72: 1151

[7] Zhang ZB, Zeng QG, Yan RM, Wang Y, Zou ZR, Zhu D. Endophytic fungus Cladosporium cladosporioides LF70 from Huperzia serrata produces Huperzine A. World J Microbiol Biotechnol 2011; 27: 479-486

[8] Goodger JQD, Whincup AL, Field AR, Holtum JAM, Woodrow IE. Variation in huperzine A and B in Australasian Huperzia species. Biochem Syst Ecol 2008; 36: 612-618

[9] Stærk D, Larsen J, Larsen LA, Olafsdottir ES, Witt M, Jaroszewski JW. Selagoline, a new alkaloid from Huperzia selago. Nat Prod Res 2004; 18: 197203

[10] Schuettpelz E, Schneider H, Smith AR, Hovenkamp P, Prado J, Rouhan G, Salino A, Sundue M, Almeida TE, Parris B, Sessa EB, Field AR, de Gasper AL, Rothfels C], Windham MD, Lehnert M, Dauphin B, Ebihara A, Lehtonen S, Schwartsburd PB, Metzgar J, Zhang LB, Kuo LY, Brownsey PJ, Kato M, Arana MD, Assis FC, Barker MS, Barrington DS, Chang HM, Chang YH, Chao YS, Chen CW, Chen DK, Chiou WL, de Oliveira Dittrich VA, Duan YF, Dubuisson JY, Farrar DR, Fawcett S, Gabriel y Galán JM, de Araújo Góes-Neto LA, Grant JR, Grusz AL, Haufler C, Hauk W, He H, Hennequin S, Hirai RY, Huiet L, Kessler M, Korall P, Labiak PH, Larsson A, León B, Li CX, Li FW, Link-Pérez M, Liu HM, Lu NT, Meza-Torres El, Miao XY, Moran R, Mynssen CM, Nagalingum N, Øllgaard B, Paul AM, Jovani JB, Perrie LR, Ponce M, Ranker TA, Schulz C, Shinohara W, Shmakov A, Sigel EM, de Souza FS, da Silva Sylvestre L, Testo W, Triana-Moreno LA, Tsutsumi C, Tuomisto H, Valdespino IA, Vasco A, Viveros RS, Weakley A, Wei R, Weststrand S, Wolf PG, Yatskievych G, Xu XG, Yan YH, Zhang L, Zhang XC, Zhou XM. A community-derived classification for extant lycophytes and ferns. J Syst Evol 2016; 54: 563-603

[11] Kristinsson H. Flowering Plants and Ferns of Iceland, 3rd edition. Reyjavik: Forlagid ehf.; 2010

[12] Halldorsdottir ES, Palmadottir RH, Nyberg NT, Olafsdottir ES. Phytochemical analysis of alkaloids from the Icelandic club moss Diphasiastrum alpinum. Phytochem Lett 2013; 6: 355-359

[13] Halldorsdottir ES, Jaroszewski JW, Olafsdottir ES. Acetylcholinesterase inhibitory activity of lycopodane-type alkaloids from the Icelandic Lycopodium annotinum ssp. alpestre. Phytochemistry 2010; 71: 149-157

[14] Bai D. Development of huperzine A and B for treatment of Alzheimer's disease. Pure Appl Chem 2007; 79: 469-479

[15] Wagner WH jr., Beitel JM. Lycopodiaceae Mirbel. In: Flora of North America, Editorial Committee, eds. Flora of North America north of Mexico, Vol. 2. Pteridophytes and Gymnosperms. New York, Oxford: Flora of North America Association; 1993: 18-37

[16] Rothmaler W. Huperzia Bernh. In: Moore D, eds. Flora Europaea, Vol. 1. London, UK: Cambridge University Press; 1993: 1-629

[17] Jonsell B, Karlsson T. Flora Nordica, Volume 1: Lycopdiaceae Polygonaceae. Stockholm: The Bergius Foundation, The Royal Swedish Academy of Sciences; 2000

[18] Lid J, Lid DT. Norsk Flora. 7th edition. Oslo: Det Norske Samlaget; 2005

[19] Mossberg B, Stenberg L. Den nya nordiska Floran. Stockholm: Bonnier Facts; 2010

[20] Øllgaard B. A revised classification of the Lycopodiaceae s. lat. Opera Bot 1987; 92: 153-178

[21] Testo W, Øllgaard B, Field A, Almeida T, Kessler M, Barrington D. Phylogenetic systematics, morphological evolution, and natural groups in neotropical Phlegmariurus (Lycopodiaceae). Mol Phylogenet Evol 2018; 125: $1-13$

[22] Field AR, Testo W, Bostock PD, Holtum JAM, Waycott M. Molecular phylogenetics and the morphology of the Lycopodiaceae subfamily Huperzioideae supports three genera: Huperzia, Phlegmariurus and Phylloglossum. Mol Phylogenet Evol 2016; 94: 635-657 
[23] Bauret L, Field AR, Gaudeul M, Selosse MA, Rouhan G. First insights on the biogeographical history of Phlegmariurus (Lycopodiaceae), with a focus on Madagascar. Mol Phylogenet Evol 2018; 127: 488-501

[24] Wikström N, Kenrick P. Phylogeny of Lycopodiaceae (Lycopsida) and the relationships of Phylloglossum drummondii Kunze based on rbcL sequences. Int J Plant Sci 1997; 158: 862-871

[25] Burnard D, Shepherd L, Perrie L, Munkacsi A. Phylogenetic relationships of New Zealand Lycopodiaceae. Plant Syst Evol 2016; 302: 661-667

[26] Ji SG, Huo KK, Wang J, Pan SL. A molecular phylogenetic study of Huperziaceae based on chloroplast rbcL and psbA-trnH sequences. J Syst Evol 2008; 46: 213-219

[27] Shrestha N, Zhang XC. On the presence of North American clubmoss Huperzia lucidula (Lycopodiaceae) in China: an intercontinental disjunction or misidentification. Phytotaxa 2015; 219: 243-252

[28] Wagner F, Beitel JM. Evidence for interspecific hybridsation in pteridophytes with subterranean mycoparasitic gametophytes. Proc Roy Soc Edinburgh 1985; 86 B: 273-281

[29] Ma X, Tan C, Zhu D, Gang DR. Is there a better source of huperzine A than Huperzia serrata? Huperzine A content of huperziaceae species in China. J Agric Food Chem 2005; 53: 1393-1398

[30] Cuthbertson D, Piljac-Žegarac ], Lange BM. Validation of a microscale extraction and high-throughput UHPLC-QTOF-MS analysis method for huperzine A in Huperzia. Biomed Chromatogr 2012; 26: 1191-1195

[31] Zhao X, Wang D, Luo H, Yang M. Simultaneous determination of three alkaloids in Huperzia serrata by UPLC-PDA and UPLC-Q/TOF-MS. Anal Methods 2015; 7: 1770-1776
[32] Lim WH, Goodger JQD, Field AR, Holtum JAM, Woodrow IE. Huperzine alkaloids from Australasian and southeast Asian Huperzia. Pharm Biol 2010; 48: 1073-1078

[33] Katoh K, Standley DM. MAFFT multiple sequence alignment software version 7: improvements in performance and usability. Mol Biol Evol 2013; 30: 772-780

[34] Silvestro D, Michalak I. RaxmIGUI: A graphical front-end for RAxML. Org Divers Evol 2012; 12: 335-337

[35] Ronquist F, Huelsenbeck JP. MrBayes 3: Bayesian phylogenetic inference under mixed models. Bioinformatics 2003; 19: 1572-1574

[36] Clement M, Posada D, Crandall KA. TCS: A computer program to estimate gene genealogies. Mol Ecol 2000; 9: 1657-1659

[37] Leigh JW, Bryant D. Popart: full-feature software for haplotype network construction. Methods Ecol Evol 2015; 6: 1110-1116

[38] Sang T, Crawford DJ, Stuessy TF. Chloroplast DNA phylogeny, reticulate evolution, and biogeography of Paeonia (Paeoniaceae). Am J Bot 1997; 84: $1120-1136$

[39] Tate JA, Simpson BB. Paraphyly of Tarasa (Malvaceae) and diverse origins of the polyploid species. Syst Bot 2003; 28: 723-737

[40] Taberlet P, Gielly L, Pautou G, Bouvet J. Universal primers for amplification of three non-coding regions of chloroplast DNA. Plant Mol Biol 1991; 17: 1105-1109 